\title{
EVALUATION OF PASSIVE AVOIDANCE LEARNING AND SPATIAL MEMORY IN RATS EXPOSED TO LOW LEVELS OF LEAD DURING SPECIFIC PERIODS OF EARLY BRAIN DEVELOPMENT
}

\author{
RAJASHEKAR RAO BARKUR ${ }^{1}$ and LAXMINARAYANA K. BAIRY ${ }^{2}$ \\ ${ }^{1}$ Manipal University, Melaka Manipal Medical College, Manipal, India \\ Department of Biochemistry \\ ${ }^{2}$ Manipal University, Kasturba Medical College, Manipal, India \\ Department of Pharmacology
}

\begin{abstract}
Objectives: Widespread use of heavy metal lead $(\mathrm{Pb})$ for various commercial purposes has resulted in the environmental contamination caused by this metal. The studies have shown a definite relationship between low level lead exposure during early brain development and deficit in children's cognitive functions. This study investigated the passive avoidance learning and spatial learning in male rat pups exposed to lead through their mothers during specific periods of early brain development. Material and Methods: Experimental male rats were divided into 5 groups: i) the normal control group (NC) $(\mathrm{N}=12)$ consisted of rat offspring born to mothers who were given normal drinking water throughout gestation and lactation, ii) the pre-gestation lead exposed group $(\mathrm{PG})(\mathrm{N}=12)$ consisted of rat offspring, mothers of these rats had been exposed to $0.2 \%$ lead acetate in the drinking water for 1 month before conception, iii) the gestation lead exposed group $(\mathrm{G})(\mathrm{N}=12)$ contained rat offspring born to mothers who had been exposed to $0.2 \%$ lead acetate in the drinking water throughout gestation, iv) the lactation lead exposed group $(\mathrm{L})(\mathrm{N}=12)$ had rat offspring, mothers of these rats exposed to $0.2 \%$ lead acetate in the drinking water throughout lactation and v) the gestation and lactation lead exposed group $(\mathrm{GL})(\mathrm{N}=12)$ contained rat offspring, mothers of these rats were exposed to $0.2 \%$ lead acetate throughout gestation and lactation. Results: The study found deficit in passive avoidance learning in the G, L and GL groups of rats. Impairment in spatial learning was found in the PG, G, L and GL groups of rats. Interestingly, the study found that gestation period only and lactation period only lead exposure was sufficient to cause deficit in learning and memory in rats. The extent of memory impairment in the L group of rats was comparable with the GL group of rats. Conclusions: So it can be said that postnatal period of brain development is more sensitive to neurotoxicity compared to prenatal exposure.
\end{abstract}

Key words:

Rats, Developing brain, Blood lead, Hippocampus, Passive avoidance learning, Morris water maze

\section{INTRODUCTION}

Lead $(\mathrm{Pb})$ has no biological role and is toxic to biological system. Lead has been widely used for various commercial and industrial purposes because of its economic value and easy availability. Lead is used in manufacturing of lead-acid batteries, ceramic glaze, plumbing materials, ammunition, wire sheathing, radiation shielding material, herbal medicine, pigments and paints [1-3]. In developing countries, environmental contamination caused by heavy metals is on the increase

Received: April 3, 2014. Accepted: November 4, 2014.

Corresponding author: L.K. Bairy, Kasturba Medical College, Manipal University, Madav nagar, Manipal-576104, Karnataka, India (e-mail: kl.bairy@manipal.edu). 
due to rapid economic development and limited regulatory infrastructure [4,5].

Epidemiological data has proven a definite relationship between low level lead exposure during early brain development and impairment in children's cognitive functions [6,7]. Studies have suggested that childhood lead exposure affects various cognitive domains such as attention, executive function, visual-motor integration, social behavior, fine-motor coordination and balance [8,9]. In children, the most widely used chelator for lead toxicity is succimer [10]. However, lead deposited in the brain cannot be removed by chemical chelating agents and reversal of the neurological deficits that are associated with elevated blood lead levels does not take place by means of chelation therapy [11].

Crucial period of brain development in humans begins in the last trimester of uterine life and continues till 2 years of age. However, in rats, this phase of brain development ends by the 4 th week of life [12].

Hippocampal formation of the brain is critical for memory storage, declarative memory and spatial navigation [13-15]. In humans, monkeys and rodents, the damage of hippocampus negatively affects the performance in various learning and memory tasks [16]. Rats with hippocampal lesions have showed impaired spatial learning in the Morris water maze test [14,17]. Kuhlmann et al. [18] found that rat pups exposed to lead during gestation and lactation period had significant impairment in water maze performance, but not rats exposed to lead after weaning. However, it would be interesting to find out whether only pre-gestation, only gestation, only lactation period of lead exposure during early brain development can cause learning and memory impairments. So, this study was taken up to evaluate and compare the learning and memory deficits, if any, in rat pups exposed to low levels of lead during specific periods of early brain development.

\section{MATERIAL AND METHODS}

The animals used in this study were adult male (200$250 \mathrm{~g})$ and female Wistar albino rats (180-210 g) and their F1 offspring. Rats were housed in polypropylene cages $(37 \times 21.5 \times 14 \mathrm{~cm})$ with a wire mesh lid and paddy husk as bedding material. Animals were maintained in $12 \mathrm{~L}: 12 \mathrm{D}$ cycle, in an air-conditioned room $\left(22^{\circ} \mathrm{C}\right)$ and controlled humidity in the central animal house facility. All rats were fed with rat pellets (Amurut feed supplies, Puna, India) and water ad libitum. The institutional animal ethical committee's (No. IAEC/KMC/07/2007-2008) approval was obtained for the study. Animals were maintained and treated according to the guidelines recommended by the Committee for the Purpose of Control and Supervision of Experiments on Animals, the Government of India.

\section{Experimental design}

Until the pregnancy in adult female rats, vaginal smears had been collected every day and pro-estrous females had been placed in separate cages along with male rats in the ratio 2:1 per cage. In the following morning, vaginal smear test was performed. The presence of spermatozoa was taken as an index of mating and pregnancy. This day was considered as GD1. Pregnant females were individually housed in maternity cages. The administration of lead $(\mathrm{Pb})$ to the animals was performed according to the previously published protocol which had produced a blood lead levels $25-35 \mu \mathrm{g} / \mathrm{dl}$ in adult rats maintained on lead $[19,20]$. This dosage was selected as the blood lead levels $25-35 \mu \mathrm{g} / \mathrm{dl}$ seen in segments of population leaving in the area of environmental lead contamination throughout the world (Toscano and Guilarte, 2005) [21]. Lead acetate solution (0.2\%) was prepared in tap water and $0.5 \mathrm{ml} / 1$ glacial acetic acid was added to prevent any precipitation of lead acetate.

The experimental pregnant rats were divided into 5 groups $(\mathrm{N}=30)$ :

- normal control $(\mathrm{NC})(\mathrm{N}=6)$,

- gestation lead exposed $(\mathrm{G})(\mathrm{N}=6)$,

- lactation lead exposed (L) $(\mathrm{N}=6)$,

- gestation and lactation lead exposed (GL) $(\mathrm{N}=6)$,

- pre-gestation lead exposed (PG) $(\mathrm{N}=6)$. 
The rats in the gestation lead exposed group $(G)$ were given $0.2 \%$ lead acetate in drinking water throughout gestation for 21 days. The rats in the lactation lead treated group (L) were allowed to drink $0.2 \%$ lead acetate in drinking water only after delivery for a period of 21 days (lactation period). The gestation and lactation lead exposed group (GL) of rats was administered $0.2 \%$ lead acetate in drinking water throughout gestation and lactation periods, which totaled to a period of 42 days. In the pre-gestation lead exposed group, female rats were administered $0.2 \%$ lead acetate in drinking water for the period of 30 days. These female rats of the pre-gestation lead exposed group were then mated with the male rats and were maintained on normal drinking water throughout the experimental period. The rats in the normal control group (NC) were given normal water to drink throughout gestation and lactation period.

Mothers of lead-exposed groups gave birth to healthy pups without any physical deformities. There was no stillbirth. On average, 3 to 4 male pups were born to each experimental pregnant rats out of which 2 male pups where randomly selected for the experiment. So, the male rat pups $(\mathrm{N}=12)$ born to normal control rats and lead exposed rats $(\mathrm{N}=12$ in each group) were our experimental animals. On the postnatal day 22, weaning of rat pups in the normal control and lead exposed groups (GL, L, G and PG) was done and they were housed in separate cages (4 rats per cage). From this point onwards, rats of all groups were allowed normal water for drinking for the rest of the experimental period. There was no mortality of rat pups at weaning.

\section{Birth weight and weight gain}

Weights of male pups born to both the normal control and lead exposed groups were measured on the day of birth and on 7 th, 14th, 21st postnatal days.

\section{Estimation of blood lead}

On the postnatal day 22, blood for lead estimation was collected from orbital veins in a heparinized vacutainer.
To meta-exchange reagent $(2.9 \mathrm{ml}), 100 \mu \mathrm{l}$ of blood was added using a micro-pipette and left undisturbed for $24 \mathrm{~h}$. The supernatant of the above solution mixture was used for estimation of blood lead by anodic stripping voltammetry using ESA-3010B lead analyzer [22].

\section{Behavioral experiments}

The behavioral tests were performed from the postnatal day 26 to 36 . Memory retention was assessed by means of the passive avoidance test and spatial memory was assessed using the Morris water maze test. Before starting the behavioral studies, the animals had been handled by the experimenter so that they were free from the experimenter induced anxiety. This was done by holding and stroking the experimental animals by hand for the duration of 2-3 min each per animal in 2 sessions with time intervals of $10 \mathrm{~min}$.

\section{Passive avoidance test}

To test the memory retention, rats were subjected to the passive avoidance learning test on the postnatal day 26 [23]. The test determines the ability of a rat to remember a foot shock delivered $24 / 48 \mathrm{~h}$ prior to the memory retention test. The passive avoidance apparatus consists of a wooden box $(50 \times 50 \times 35 \mathrm{~cm})$ with a larger, brightly illuminated compartment and a smaller $(15 \times 15 \times 15 \mathrm{~cm})$, dark compartment with grid floor, which was attached to a shock source. At the beginning of the experiment, a rat was placed in the illuminated larger compartment for exploration. The door between the 2 compartments was kept open during this phase of the experimental period. The rat was allowed to explore both of the compartments for $5 \mathrm{~min}$. This was followed by 3 test trials of 5 min each with an interval of $30 \mathrm{~min}$. At the end of $3 \mathrm{rd}$ test trial, as soon as the animal had stepped into the dark compartment, the door between the 2 compartments was closed and a single foot shock was delivered through the grid floor $(50 \mathrm{~Hz}, 1.5 \mathrm{~mA}$, for $1 \mathrm{~s}$ ). The rat was held in the dark compartment for an additional $10 \mathrm{~s}$ to allow the animal to form an 
association between the properties of the chamber and the foot shock. It was then returned to its home cage. This part of the experiment is called exploration and learning. The memory retention test was done $24 \mathrm{~h}$ and $48 \mathrm{~h}$ after the foot shock. In the memory retention test, the rat was placed in the bright chamber and time taken (the step-through latency) to enter the dark compartment for the 1st time was recorded using a stop-watch. A maximum of $180 \mathrm{~s}$ was given for the rat to explore. Fraction of time spent in the dark and bright compartments for each rat was noted. Normal rats avoided entering the dark chamber, where they received shock on the previous day, suppressing their normal behavior of exploring the dark compartment. Decrease in entry latency and decreased time spent in bright compartment suggested poor memory retention.

\section{Morris water maze test}

To test the spatial memory, rats were subjected to the Morris water maze test from the postnatal day 30 till 36 [24]. The Morris water maze experiment consists of learning session (for 5 days) and a memory retention test that took place $24 \mathrm{~h}$ after the last learning session.

The water maze apparatus comprised of a white circular water tank of $1.8 \mathrm{~m}$ in diameter situated in a room illuminated by white fluorescent lamps. Along the edge of the water tanks, 4 points were marked and these divided the pool into 4 equal quadrants. A square shaped escape platform $(4 \times 4$ inches size) was submerged $(2 \mathrm{~cm}$ below the water surface level) in 1 of the quadrant and this quadrant was called the target quadrant (TQ). The tank was filled with $40 \mathrm{~cm}$ of tap water with the temperature of $26^{\circ} \mathrm{C}$. Before the experiment, powdered non-fat milk had been added to make the water opaque. For facilitating the spatial orientation in experimental animals, visual cues were placed around the water tank. Positions of the cues were kept unchanged throughout the period of experiment. A video camera suspended from the ceiling above the tank was used to record the experiment. Animal tracks in the water maze were analyzed using the video camera and Panlab Smart Version 2.5 video tracking software, Barcelona, Spain.

The rats were trained in the water maze in 5 sessions on 5 consecutive days; each session had 2 trials per animal with an interval of $2 \mathrm{~h}$ between the trials. During each trial, different start points in the water tank were used. In each trial, time taken by the rats to reach the hidden platform was recorded and they were allowed to rest for $10 \mathrm{~s}$ on the platform before removal from the tank. The experimenter guided rats to the platform and if they failed to find the platform within 2 min, a maximum time score of 2 min was assigned.

Twenty-four hours after the last learning session, rats were subjected to the memory retention test. The memory retention session lasted $30 \mathrm{~s}$. In this memory retention test, the escape platform was removed from the target quadrant and rat a was released in the quadrant opposite to the target quadrant. Time taken to reach the target quadrant, time spent in the target quadrant and distance traveled in the target quadrant were measured. Greater latency to reach the target quadrant and less time spent in the target quadrant were indicative of spatial memory impairment.

\section{STATISTICAL ANALYSIS}

Data was analyzed using the analysis of variance (ANOVA) followed by Bonferroni's multiple comparison tests as post hoc test (Graph pad prism 4 software). Values were expressed in terms of mean \pm standard deviation $(\mathrm{M} \pm \mathrm{SD})$. $\mathrm{P}<0.05$ were considered as significant.

\section{RESULT}

\section{Birth weight and weight gain}

There was no significant difference between birth weight and weight gain in the lead exposed groups of rat pups (GL, L, G and PG), when compared to the normal control group (NC) on the day of birth, 7th, 14th and 21st postnatal day (Table 1). 
Table 1. Body weight of rats of different groups

\begin{tabular}{|c|c|c|c|c|}
\hline \multirow[t]{2}{*}{$\begin{array}{l}\text { Study group } \\
(\mathrm{N}=12)\end{array}$} & \multicolumn{4}{|c|}{$\begin{array}{c}\text { Body weight }^{\mathrm{a}} \\
(\mathrm{M} \pm \mathrm{SD}) \\
{[\mathrm{g}]}\end{array}$} \\
\hline & at birth & $\begin{array}{l}\text { postnatal } \\
\text { day } 7\end{array}$ & $\begin{array}{l}\text { postnatal } \\
\text { day } 14\end{array}$ & $\begin{array}{c}\text { postnatal } \\
\text { day } 21\end{array}$ \\
\hline$\overline{\mathrm{NC}}$ & $5.50 \pm 0.83$ & $11.03 \pm 0.85$ & $18.96 \pm 1.86$ & $25.17 \pm 1.75$ \\
\hline PG & $5.42 \pm 0.47$ & $11.60 \pm 0.92$ & $18.63 \pm 1.49$ & $25.75 \pm 1.29$ \\
\hline G & $5.79 \pm 0.62$ & $11.68 \pm 0.91$ & $18.44 \pm 1.43$ & $25.08 \pm 1.38$ \\
\hline $\mathrm{L}$ & $5.70 \pm 0.69$ & $10.89 \pm 0.78$ & $18.92 \pm 1.72$ & $25.17 \pm 1.70$ \\
\hline GL & $5.56 \pm 0.54$ & $11.63 \pm 0.63$ & $18.40 \pm 1.16$ & $25.83 \pm 1.40$ \\
\hline
\end{tabular}

a There is no significance difference in body weight between the lead exposed groups as compared to the normal control group.

$\mathrm{NC}$ - normal control; PG - pregestation lead exposed; G - gestation lead exposed; L - lactation lead exposed; GL - gestation and lactation lead exposed.

$\mathrm{M}$ - mean; SD - standard deviation.

\section{Estimation of blood lead level on postnatal day 22}

Blood lead level (mg/dl) was significantly high in the gestation and lactation lead exposed group (GL) of rats $(32 \pm 1.97)$ followed by the lactation lead exposed group (L) (26.65 \pm 4.08$)$, gestation lead exposed group $(5.3 \pm 1.63)$, pre-gestation lead exposed group (PG) $(3.02 \pm 0.76)$, normal control group (NC) (0.18 \pm 0.06$)$ (Table 2).

\section{Passive avoidance test}

\section{Exploration test}

We did not find any difference in the control and lead exposed groups of rats (GL, L, G and PG) in the time spent in the dark and bright chamber during exploration in the passive avoidance test before receiving the foot shock. The following data shows the time (in s) spent in the dark compartment during exploration by different groups of rats: NC: $252.92 \pm 26.67, \mathrm{PG}: 245.83 \pm 21.20$, G: 251.25 \pm 19.55 , L: $249.17 \pm 17.30, \mathrm{GL}: 248.33 \pm 25.44$.

\section{Retention test after $24 \mathrm{~h}$}

The gestation and lactation lead exposed group (GL), $\mathrm{L}$ and $\mathrm{G}$ groups of rats revealed impaired memory retention as they showed decreased latency (in s) to enter the

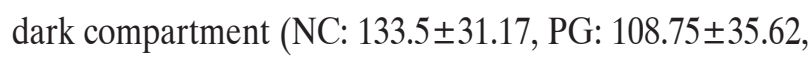

Table 2. Blood lead $(\mathrm{Pb})$ level in rats of different groups (on the postnatal day 22)

\begin{tabular}{lc}
\hline $\begin{array}{c}\text { Study group } \\
(\mathrm{N}=10)\end{array}$ & $\begin{array}{c}\mathrm{Pb} \\
(\mathrm{M} \pm \mathrm{SD})\end{array}$ \\
\hline $\mathrm{NC}$ & {$[\mu \mathrm{g} / \mathrm{dl}]$} \\
$\mathrm{PG}$ & $0.18 \pm 0.06$ \\
$\mathrm{G}$ & $3.02 \pm 0.76$ \\
$\mathrm{~L}$ & $5.30 \pm 1.63^{* * *}$ \\
$\mathrm{GL}$ & $26.65 \pm 4.08^{* * *, \# \#, \# \#}$ \\
\hline
\end{tabular}

Statistical significance of results (one way ANOVA, Bonferroni's test): *** $\mathrm{p}<0.001$, when compared with NC; ${ }^{*} \mathrm{p}<0.001$, when compared with PG; ${ }^{\# \#} \mathrm{p}<0.001$, when compared with $\mathrm{G}$; ${ }^{\# \#} \mathrm{p}<0.001$, when compared with L.

Other abbreviations as in Table 1.

G: $70 \pm 23.74$, L: 40.17 \pm 19.6 , GL: $34.42 \pm 13.96)$ and GL, $\mathrm{L}$ and $\mathrm{G}$ groups of rats spent less time (in s) in the bright compartment as compared to the $\mathrm{PG}$ and $\mathrm{NC}$ groups of rats (NC: 151.3 \pm 20.24 , PG: $137.1 \pm 20.17$, G: 87.08 \pm 28.96 , L: 70.25 \pm 27.77 , GL: 68.58 \pm 36.52 ) (Figure 1).

\section{Retention test after $48 \mathrm{~h}$}

Memory impairment in the GL, L, and G groups of rats was evident as the entry latency data of this test was similar to the latency (in s) to enter the dark compartment 

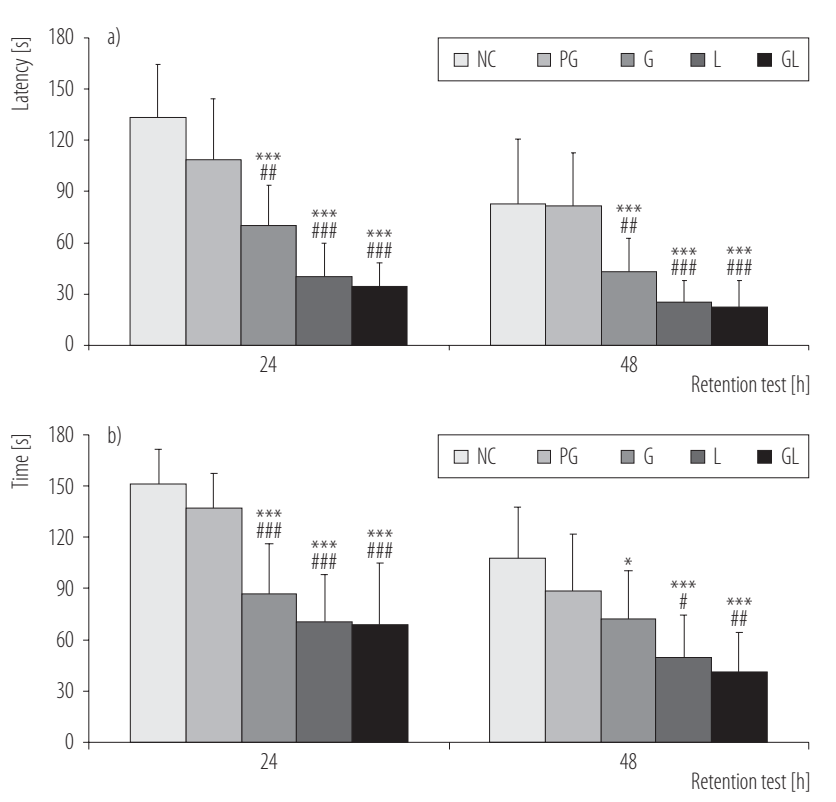

Abbreviations as in Table 1.

Statistical significance of results (one way ANOVA, Bonferroni's test): $* \mathrm{p}<0.05,{ }^{* *} \mathrm{p}<0.01,{ }^{* * *} \mathrm{p}<0.001$, when compared with NC; ${ }^{\#} \mathrm{p}<0.05,{ }^{\# \#} \mathrm{p}<0.01,{ }^{\# \#} \mathrm{p}<0.001$, when compared with PG. Each data represents mean \pm standard deviation $(\mathrm{M} \pm \mathrm{SD})(\mathrm{N}=12$ in each group).

Fig. 1. Passive avoidance performance of various rat groups (on the postnatal day 27): a) latency to enter the dark compartment, b) time spent in bright compartment

after $24 \mathrm{~h}$ (NC: 82.92 \pm 37.75 , PG: 81.83 \pm 31.06 , G: 43.33 \pm 19.35 , L: $25 \pm 12.82$, GL: $22.25 \pm 15.41$ ) and the GL, $\mathrm{L}$ and $\mathrm{G}$ group of rat spent less time (in $\mathrm{s}$ ) in the bright compartment as compared to the $\mathrm{PG}$ and $\mathrm{NC}$ groups of rats (NC: $107.5 \pm 30.26, \mathrm{PG}: 88.33 \pm 33.39$, G: $72.08 \pm 28.03$, L: 49.58 \pm 24.81 , GL: 41.08 \pm 22.99 ) (Figure 1).

\section{Morris water maze test}

\section{Learning sessions}

During the learning sessions, latency to reach on to the escape platform was measured in s. In the 1st session, rats in all groups took equal amount of time to reach the escape platform. In the 2nd session, rats in all groups were able to reach the escape platform, much faster than during 1 st session. In the sessions no. 3, 4, and 5, rats in all groups

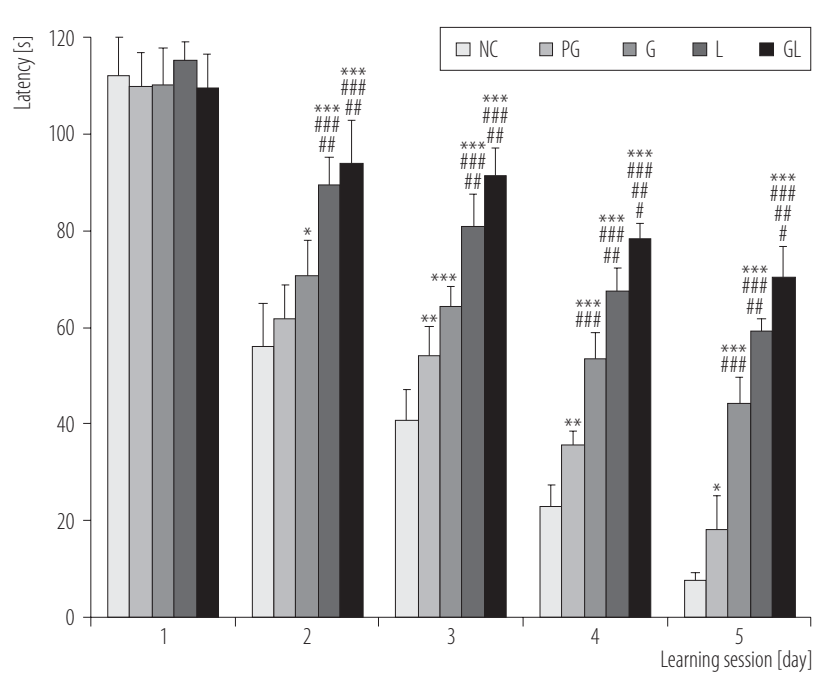

Abbreviations as in Table 1.

Statistical significance of results (one way ANOVA, Bonferroni's test): ${ }^{*} \mathrm{p}<0.05,{ }^{* *} \mathrm{p}<0.01,{ }^{* * *} \mathrm{p}<0.001$, when compared with NC, ${ }^{\# \#} \mathrm{p}<0.001$, when compared with $\mathrm{PG},{ }^{\# \#} \mathrm{p}<0.001$, when compared with $\mathrm{G},{ }^{*} \mathrm{p}<0.01$, when compared with $\mathrm{L}$. Each data represents $\mathrm{M} \pm \mathrm{SD}(\mathrm{N}=6$ in each group).

Fig. 2. Latency to escape on to the platform during learning sessions in water maze of different rat groups (postnatal day 30-34)

learnt to reach the escape platform much faster and their escape latency decreased progressively from session to session. However, lead treated groups of rats were taking more time than normal control animals to reach the escape platform (Figure 2).

\section{Morris water maze retention test}

Latency to enter target quadrants

There was a significant increase in latency to enter the target quadrants in the lead exposed group, namely the GL, L, G and PG groups of rats as compared to the NC (NC: $1.68 \pm 0.36, \mathrm{PG}: 2.85 \pm 0.95$, G: $4.83 \pm 1.92$,

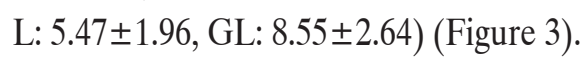

\section{Time spent in target quadrant}

Spatial memory impairment in rats is also indicated by the time spent in the target quadrant. The decreased time spent in the target quadrant indicates spatial 

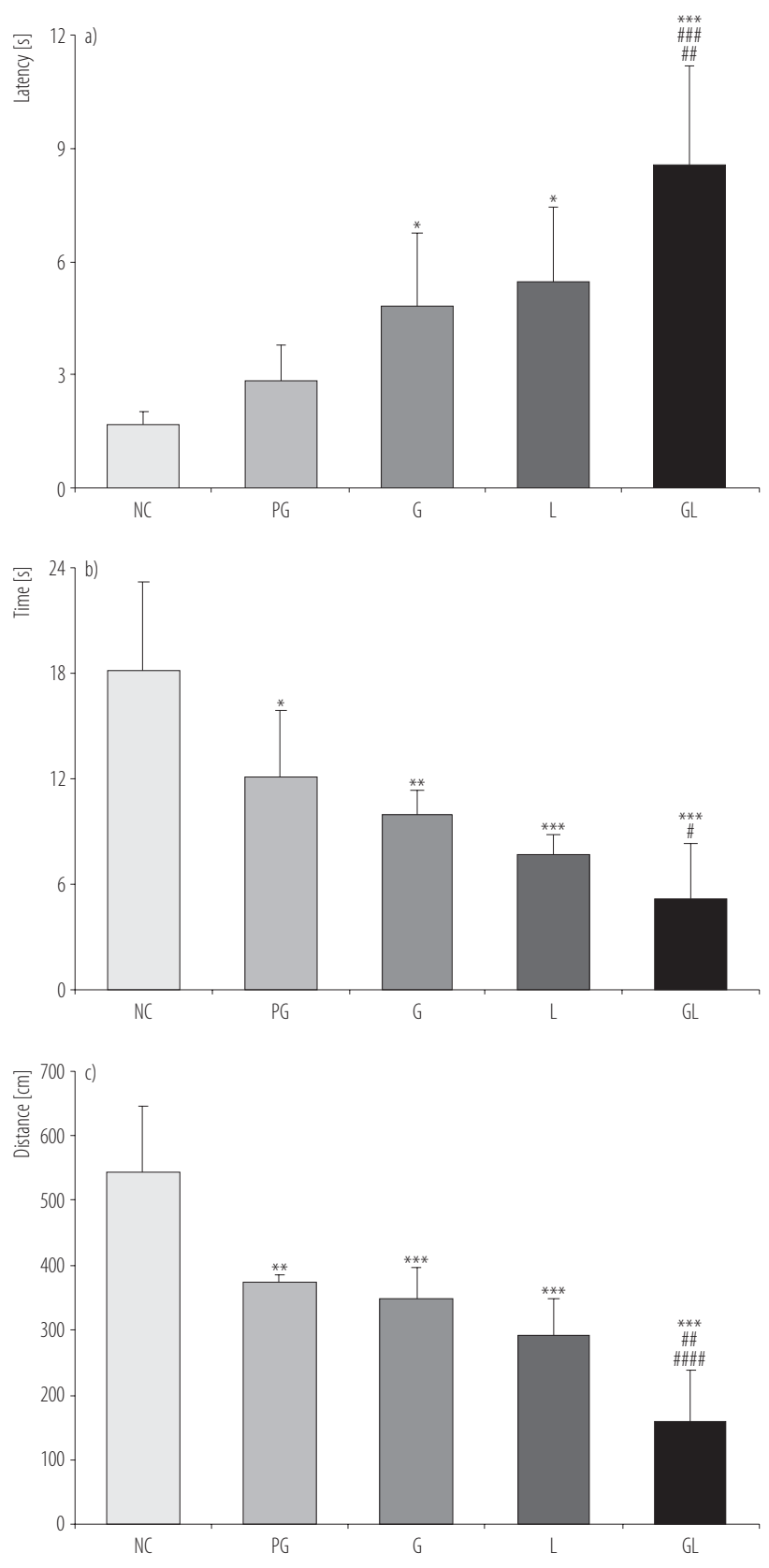

Abbreviations as in Table 1.

Statistical significance of results (one way ANOVA, Bonferroni's test):

${ }^{*} \mathrm{p}<0.05,{ }^{* *} \mathrm{p}<0.01,{ }^{* * *} \mathrm{p}<0.001$, when compared with NC,

${ }^{\#} \mathrm{p}<0.05,{ }^{\# \#} \mathrm{p}<0.001$, when compared with $\mathrm{PG},{ }^{\# \#} \mathrm{p}<0.05$,

$\# \# \#$ p $<0.001$, when compared with $\mathrm{G}$.

Each data represents $\mathrm{M} \pm \mathrm{SD}(\mathrm{N}=6$ in each group).

Fig. 3. Performance in the water maze retention test of various rat groups on the postnatal day 36: a) latency to enter the target quadrant, b) time spent in target quadrant, c) distance travelled in target quadrant memory impairment. The gestation and lactation leadexposed group (GL), L, G and PG groups of rats spent significantly less time in the target quadrant when compared to the NC group (NC: $18.10 \pm 5.09$, PG: 12.12 \pm 3.81 , G: $9.98 \pm 1.37$, L: $7.67 \pm 1.21$, GL: 5.20 \pm 3.15 ) (Figure 3).

\section{Distance traveled in target quadrant}

This data supplemented the results of time spent in the target quadrant data. The gestation and lactation lead exposed group (GL), L, G and PG groups of rats showed significantly shorter distance traveled in the target quadrant when compared to the NC group (NC: $545.17 \pm 100.72$, PG: $374.11 \pm 12.40$, G: $348.83 \pm 48.06$, L: $291.00 \pm 57.20$, GL: 158.71 \pm 78.80 ) (Figure 3).

Video tracking of representative rats belonging to various groups during memory retention test $24 \mathrm{~h}$ after the last learning session in the water maze is given in the Figure 4.

\section{DISCUSSION}

There was no significance difference between the birth weight and weight gain (on 7th, 14th and 21st postnatal day) in the lead exposed groups of rat pups (GL, L, G and PG), when compared to the normal control group (NC). We did not find any still birth and mortality at weaning in the lead exposed groups. So, it can be said that the low level of environmentally relevant lead exposure dosage used in the experiment did not cause any alteration in general health of lead exposed animals.

Blood lead level was the highest in the GL group of rats which had the longest time of lead exposure. This was followed by the L, G, PG and NC group of rats, respectively. The passive-avoidance test exploits the rodent's preference for darkness and assesses the long-term memory in it [25]. In our study, we did not find any difference in exploration behavior between the control and lead-exposed groups of rats (GL, L, G and PG). During the retention test (after $24 \mathrm{~h}$ and $48 \mathrm{~h}$ ), the GL, L and G groups of lead exposed rats showed lower latency to enter the dark 


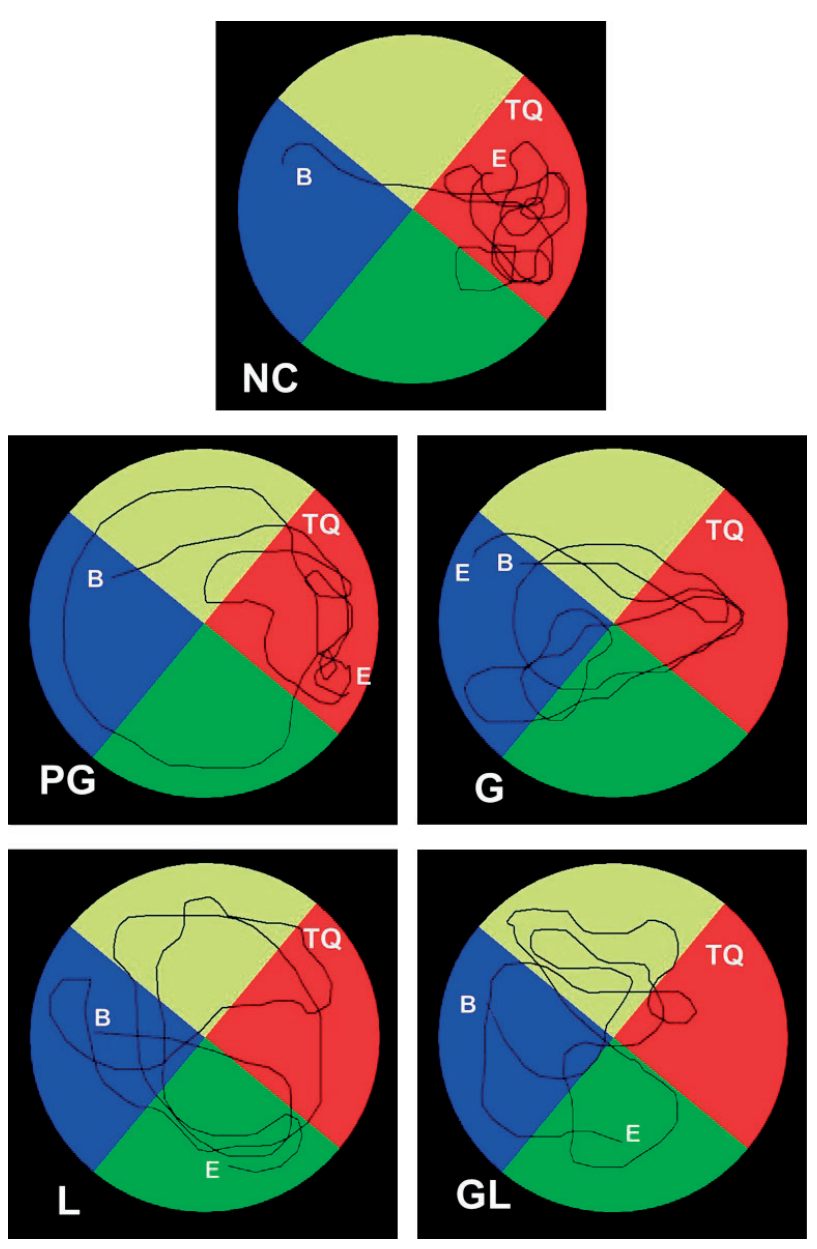

PG, G, L and GL group of rats spent less time, and traveled a short distance in the target quadrant during the water maze test indicating spatial memory impairment.

$\mathrm{B}$ - beginning of the track; TQ - target quadrant; E - end of the track. Other abbreviations as in Figure 1.

Fig. 4. Video tracking of representative rats belonging to different groups during memory retention test $24 \mathrm{~h}$ after last learning session in water maze

compartment than the control group and also they spent less time in the bright compartment indicating lead induced memory impairment.

De Oliveira et al. [26] found that rats exposed to low level of lead from the gestation day 11 till the postnatal day 28 had significantly reduced latency values in the step-through inhibitory avoidance memory task. In a study conducted by Moreira et al. [27], rat pups exposed to lead acetate during pregnancy and lactation showed a decreased exploratory behavior and impairment of learning and memory in the shuttle box test. However, in this study, lead exposure only during lactation (L group) and only during gestation period ( $\mathrm{G}$ group) caused memory deficit in the passive avoidance test. The extent of memory deficit in the passive avoidance test in the L group was comparable with that of the GL group (lead exposure period of 42 days) even though the period of exposure in L group was shorter (21 days). The $G$ group which had lead exposure for the period of 21 days showed memory impairment in the passive avoidance test which is comparatively shorter than the L group. The impairment seen in the GL, L, and G group may have been related to a possible inhibitory action of lead on immature hippocampal neurons. Lead by interfering with synapse formation might have contributed to deficits in passive avoidance memory formation. Hippocampal dentate granule synapses gets stabilized after $6-8 \mathrm{~h}$ of learning. Neural cell adhesion molecule (NCAM) plays an important role in this process by influencing dendritic expansion and spine density [28]. The synthesis NCAM is affected by lead [29].

The Morris water maze (MWM) test is used to test the spatial memory in rodents to locate a hidden platform in the pool of water using visual clues kept near the water maze [14] and is closely associated with the number of granule cell neurogenesis in the dentate gyrus (DG) of hippocampus [30]. During the learning session (2nd to 5th) of the water maze test, rats in all groups showed progressive decrease in escape latency from session to session. However, lead treated groups of rats, namely the GL, L and G groups were taking more time than normal control animals to reach the escape platform. In the retention test $24 \mathrm{~h}$ after the learning session, there was a significant increase in latency to enter the target quadrants in the GL, L and G groups of rats. There was also significant reduction in time spent and the distance traveled in the target quadrant in the GL, L, G and PG groups. This confirms severe spatial memory impairment in lead 
exposed groups especially in the GL, G and L groups which may be due to the attention deficit.

Previous studies have found that chronic lead exposure in Wistar rats during gestation and lactation resuld in decreased learning performances in the water maze test $[18,31]$ and cause damage to mitochondria, microfilaments, and microtubules in hippocampal neurons [32]. Chang et al. [33] showed spatial learning deficits in the Morris water maze test, in rats exposed to $0.2 \%$ lead acetate in the drinking water through their mothers from the gestational day 15 to the postnatal day 21. Yang et al. [34] and Wang et al. [35] concluded from their study that exposure to lead during only gestational period and only lactation period is sufficient to cause spatial memory deficits in the Morris water maze test in young adult offspring respectively.

In this study, it has been demonstrated that lead exposure during only gestation period and only lactation period produces significant impairment in water maze test. Cognitive deficit in the $\mathrm{L}$ group was comparable to the GL group even though the period of lead exposure was much shorter (L group: 21 days vs. GL group: 42 days).

Exposure to lead during early brain development produces hippocampal synaptic plasticity deficits and affects longterm potentiation (LTP) and spatial memory in young adult rats $[36,37]$. The reason for this phenomenon has been attributed to selective inhibition of N-methyl-D-aspartate subtype of excitatory receptors (NMDAR) by lead [38,39]. Lead alters the expression of the NMDAR subunits resulting in the defective NMDAR structure affecting the hippocampal development and maturation $[35,36,40]$. Lead is believed to influence the expression of hippocampal DNA methyltransferases and methyl cytosine-binding proteins which are involved in early brain development process [41]. Lead exposure from the gestation day 0 to the postnatal day 21 in rats, enhances oxidative stress and alters the apoptosis process in developing hippocampal neurons [42]. This study has revealed that the gestation period (G group) and only lactation period ( $\mathrm{L}$ group) lead exposure causes significant learning and memory retrieval deficits in young offspring both in the passive avoidance test and Morris water maze test. Interestingly, in both of the above tests the extent of memory impairment in the L group of rats was comparable with the GL group of rats. However, pre-gestation lead exposure had minimal ill effects on memory impairment as compared to other lead exposed groups. It can also be noted that, blood lead level on the postnatal day 22 in the $G$ group $(5.30 \pm 1.63 \mu \mathrm{g} / \mathrm{dl})$ were almost similar to the PG group $(3.02 \pm 0.76 \mu \mathrm{g} / \mathrm{dl})$. Nevertheless, the $G$ group showed significant memory impairment as compared to the PG group. This fact proves that it was the period of lead exposure during brain development which was responsible for extent of memory impairment seen in the $G$ group rather than blood lead level at the time of learning and memory assessment. This fact holds true also for the memory impairment seen in the $\mathrm{L}$ and GL group of rats.

\section{CONCLUSIONS}

In conclusion, this study demonstrates that lactation period brain development is a sensitive period as far as lead exposure is concerned. The reasons for this may be numerous. But, we hypothesize that development of dentate gyrus of hippocampus, which occurs mainly from the postnatal day 1 to the postnatal day 19 [43], gets affected as a consequence of lead exposure in the lactation period. The 2nd reason may consist in the fact that postnatal neuronal differentiation and synaptogenesis might have been affected by lead exposure from the postnatal day 1 to 21 in both the L and GL groups of rats. So, it can be said that the postnatal period of brain development is more sensitive to lead neurotoxicity when compared to that of prenatal period.

\section{ACKNOWLEDGMENTS}

The authors thank the Manipal University, India for providing the infrastructure facilities. 


\section{REFERENCES}

1. Falk H. International environmental health for the pediatrician: Case study of lead poisoning. Pediatrics. 2003;112(1 Pt 2):259-64.

2. Agency for Toxic Substances and Disease Registry (ATSDR) Toxicological profile for lead. Atlanta (GA): US Department of Health and Human Services; 2007. p. 102-225.

3. Acharya S. Lead between the lines. Nat Chem. 2013; 5(10):894, http://dx.doi.org/10.1038/nchem.1761.

4. Yáñez L, Ortiz D, Calderón J, Batres L, Carrizales L, Mejía J, et al. Overview of human health and chemical mixtures: Problems facing developing countries. Environ Health Perspect. 2002;110 Suppl 6:901-9.

5. Trasande L, Massey RI, DiGangi J, Geiser K, Olanipekun AI, Gallagher L. How developing nations can protect children from hazardous chemical exposures while sustaining economic growth. Health Aff (Millwood). 2011;30(12):2400-9, http://dx.doi.org/10.1377/hl thaff.2010.1217.

6. Needleman HL. The current status of childhood low-level lead toxicity. Neurotoxicology. 1993;14(2-3):161-6.

7. Markowitz M. Lead poisoning: A disease for the next millennium. Curr Probl Pediatr. 2000;30(3):62-70, http://dx. doi.org/10.1067/mps.2000.104053.

8. Lanphear BP, Dietrich K, Auinger P, Cox C. Cognitive deficits associated with blood lead concentrations $10 \mathrm{microg} / \mathrm{dL}$ in US children and adolescents. Public Health Rep. 2000; 115(6):521-9.

9. Bellinger DC. Effect modification in epidemiological studies of low-level neurotoxicant exposures and health outcomes. Neurotoxicol Teratol. 2000;22(1):133-40, http:// dx.doi.org/10.1016/S0892-0362(99)00053-7.

10. Warniment C, Tsang K, Galazka SS. Lead poisoning in children. Am Fam Physician. 2010;81(6):751-7.

11. Rogan WJ, Dietrich KN, Ware JH, Dockery DW, Salganik M, Radcliffe J, et al. Treatment of Lead-Exposed Children Trial Group. The effect of chelation therapy with succimer on neuropsychological development in children exposed to lead. N Engl J Med. 2001;344(19):1421-6, http://dx.doi. org/10.1056/NEJM200105103441902.

12. Rice D, Barone S Jr. Critical periods of vulnerability for the developing nervous system: Evidence from humans and animal models. Environ Health Perspect. 2000;108 Suppl 3:511-33.

13. O'Keefe J, Nadel L. The hippocampus as a cognitive map. Oxford: Oxford University Press; 1978. p. 62-89.

14. Morris RGM, Garrud P, Rawlins JNP, O'Keefe J. Place navigation impaired in rats with hippocampal lesions. Nature. 1982;297(5868):681-3, http://dx.doi.org/10. 1038/297681a0.

15. Fortin NJ, Agster KL, Eichenbaum HB. Critical role of the hippocampus in memory for sequences of events. Nat Neurosci. 2002;5(5):458-62, http://dx.doi.org/10.1038/nn834.

16. Eichenbaum H. The hippocampus and declarative memory: Cognitive mechanisms and neural codes. Behav Brain Res. 2001;127(1-2):199-207, http://dx.doi.org/10.1016/S01 66-4328(01)00365-5.

17. Pearce JM, Roberts AD, Good M. Hippocampal lesions disrupt navigation based on cognitive maps but not heading vectors. Nature. 1998;396(6706):75-7, http://dx.doi. org/10.1038/23941.

18. Kuhlmann AC, McGlothan JL, Guilarte TR. Developmental lead exposure causes spatial learning deficits in adult rats. Neurosci Lett. 1997;233(2-3):101-4, http://dx.doi. org/10.1016/S0304-3940(97)00633-2.

19. Jaako-Movits K, Zharkovsky T, Romantchik O, Jurgenson M, Merisalu E, Heidmets LT, et al. Developmental lead exposure impairs contextual fear conditioning and reduces adult hippocampal neurogenesis in the rat brain. Int J Dev Neurosci. 2005;23(7):627-35, http://dx.doi.org/10.10 16/j.ijdevneu.2005.07.005.

20. Chen HH, Ma T, Paul IA, Spencer JL, Ho IK. Developmental lead exposure and two-way active avoidance training alter the distribution of protein kinase $\mathrm{C}$ activity in the rat hippocampus. Neurochem Res. 1997;22(9): 1119-25, http://dx.doi.org/10.1023/A:1027365202328. 
21. Toscano CD, Guilarte TR. Lead neurotoxicity: From exposure to molecular effects. Brain Res Rev. 2005;49(3):529-54, http://dx.doi.org/10.1016/j.brainresrev.2005.02.004.

22. Kuruvilla A, Pillay VV, Venkatesh T, Adhikari P, Chakrapani M, Clark CS, et al. Portable lead analyzer to locate source of lead. Indian J Pediatr. 2004;71(6):495-9, http://dx.doi. org/10.1007/BF02724287.

23. Bureš J, Burešová $\mathrm{O}$, Huston JP. Techniques and basic experiments for the study of brain and behavior. 2nd ed. Amsterdam, New York: Elsevier; 1983. p. 95-7, 148-60.

24. D'Hooge R, de Deyn PP. Applications of the Morris water maze in the study of learning and memory. Brain Res Rev. 2001;36(1):60-90， http://dx.doi.org/10.1016/S0165-01 73(01)00067-4.

25. Dawson GR, Heyes CM, Iversen SD. Pharmacological mechanisms and animal models of cognition. Behav Pharmacol. 1992;3(4):285-97, http://dx.doi.org/10.1097/00 008877-199208000-00003.

26. De Oliveira FS, Viana MR, Antoniolli AR, Marchioro M. Differential effects of lead and zinc on inhibitory avoidance learning in mice. Braz J Med Biol Res. 2001;34(1):117-20, http://dx.doi.org/10.1590/S0100-879X2001000100014.

27. Moreira EG, Vassilieff I, Vassilieff VS. Developmental lead exposure: Behavioral alterations in the short and long term. Neurotoxicol Teratol. 2001;23(5):489-95, http://dx.doi. org/10.1016/S0892-0362(01)00159-3.

28. Doyle E, Nolan PM, Bell R, Regan CM. Intraventricular infusions of anti-neural cell adhesion molecules in a discrete posttraining period impair consolidation of a passive avoidance response in the rat. J Neurochem. 1992;59(4):1570-3, http://dx.doi.org/10.1111/j.1471-4159.1992.tb08477.x.

29. Cookman GR, King W, Regan CM. Chronic low-level lead exposure impairs embryonic to adult conversion of the neural adhesion molecule. J Neurochem. 1987;49(2):399-403, http://dx.doi.org/10.1111/j.1471-4159.1987.tb02879.x.

30. Drapeau E, Mayo W, Aurousseau C, Le Moal M, Piazza PV, Abrous DN. Spatial memory performance of aged rats in the water maze predicts level of hippocampal neurogenesis.
Proc Natl Acad Sci U S A. 2003;100(24):14385-90, http:// dx.doi.org/10.1073/pnas.2334169100.

31. Kahloula K, Slimani M, Dubois M, Bonnet J. D-cycloserine enhances spatial learning performances of rats chronically exposed to lead during the developmental period. Afr J Neurol Sci. 2009;28(1):67-77, http://dx.doi.org/10.43 14/ajns.v28i1.55141.

32. Xu J, Yan HC, Yang B, Tong LS, Zou YX, Tian Y. Effects of lead exposure on hippocampal metabotropic glutamate receptor subtype 3 and 7 in developmental rats. J Negat Results Biomed. 2009;8:5, http://dx.doi.org/10.1186/1477-5751-8-5.

33. Chang W, Chen J, Wei QY, Chen XM. Effects of Brn-3a protein and RNA expression in rat brain following lowlevel lead exposure during development on spatial learning and memory. Toxicol Lett. 2006;164(1):63-70, http://dx.doi. org/10.1016/j.toxlet.2005.11.011.

34. Yang Y, Ma Y, Ni L, Zhao S, Li L, Zhang J, et al. Lead exposure through gestation-only caused long-term learning/memory deficits in young adult offspring. Exp Neurol. 2003;184(1):489-95, http://dx.doi.org/10.1016/S00144886(03)00272-3.

35. Wang XM, Liu WJ, Zhang R, Zhou YK. Effects of exposure to low-level lead on spatial learning and memory and the expression of mGluR1, NMDA receptor in different developmental stages of rats. Toxicol Ind Health. 2013;29(8):686-96, http://dx.doi.org/10.1177/0748233712436641.

36. Nihei MK, Desmond NL, McGlothan JL, Kuhlmann AC, Guilarte TR. N-methyl-D-aspartate receptor subunit changes are associated with lead- induced deficits of long-term potentiation and spatial learning. Neuroscience. 2000;99(2):233-42, http://dx.doi.org/10.1016/S0306$4522(00) 00192-5$.

37. Guilarte TR, Toscano CD, McGlothan JL, Weaver SA. Environmental enrichment reverses cognitive and molecular deficits induced by developmental lead exposure. Ann Neurol. 2003;53(1):50-6, http://dx.doi.org/10.1002/ana.10399.

38. Alkondon M, Costa AC, Radhakrishnan V, Aronstam RS, Albuquerque EX. Selective blockade of NMDA-activated 
channel currents may be implicated in learning deficits caused by lead. FEBS Lett. 1990;261(1):124-30, http:// dx.doi.org/10.1016/0014-5793(90)80652-Y.

39. Gavazzo P, Gazzoli A, Mazzolini M, Marchetti C. Lead inhibition of NMDA channels in native and recombinant receptors. Neuroreport. 2001;12(14):3121-5, http://dx.doi. org/10.1097/00001756-200110080-00028.

40. Guilarte TR, McGlothan JL, Nihei MK. Hippocampal expression of N-methyl-D-aspartate receptor (NMDAR1) subunit splice variant mRNA is altered by developmental exposure to $\mathrm{Pb}(2+)$. Brain Res Mol Brain Res. 2000;76(2):299-305, http://dx.doi.org/10.1016/S0169328X(00)00010-3.
41. Schneider JS, Kidd SK, Anderson DW. Influence of developmental lead exposure on expression of DNA methyltransferases and methyl cytosine-binding proteins in hippocampus. Toxicol Lett. 2013;217(1):75-81, http://dx.doi.org/10.1016/j.toxlet.2012.12.004.

42. Lu X, Jin C, Yang J, Liu Q, Wu S, Li D, et al. Prenatal and lactational lead exposure enhanced oxidative stress and altered apoptosis status in offspring rats' hippocampus. Biol Trace Elem Res. 2013;151(1):75-84, http://dx.doi.org/ 10.1007/s12011-012-9531-5.

43. Bayer SA, Altman J, Russo RJ, Zhang X. Timetables of neurogenesis in the human brain based on experimentally determined patterns in the rat. Neurotoxicology. 1993;14(1):83-144.

This work is available in Open Access model and licensed under a Creative Commons Attribution-NonCommercial 3.0 Poland License - http://creativecommons.org/ licenses/by-nc/3.0/pl/deed.en. 